Cite as: Haasen, C., Eiroa-Orosa, F. J., Verthein, U., Soyka, M., Dilg, C., Schäfer, I., \& Reimer, J. (2009).

Effects of heroin-assisted treatment on alcohol consumption: findings of the German randomized

controlled trial. Alcohol, 43(4), 259-264. https://doi.org/10.1016/j.alcohol.2009.02.007

\title{
Effects of heroin-assisted treatment on alcohol consumption: findings of the German
}

\section{Randomized Controlled Trial}

\section{Haasen, C., Eiroa, F. J., Verthein, U., Soyka, M., Dilg, C., Schäfer. I., Reimer, J.}

Corresponding author: Christian Haasen. haasen@uke.uni-hamburg.de. Centre for Interdisciplinary Addiction Research, University Medical Centre Eppendorf Hamburg, Martinistr. 52. 20246 Hamburg. Germany. Tel. 040 / 42803-7901. Fax 040 / 42803-8351.

Francisco Jose Eiroa Orosa. feiroa@gmail.com. Centre for Interdisciplinary Addiction Research, University Medical Centre Eppendorf Hamburg, Martinistr. 52. 20246 Hamburg. Germany.

Uwe Verthein. verthein@sozialwiss.uni-hamburg.de. Centre for Interdisciplinary Addiction Research, University Medical Centre Eppendorf Hamburg, Martinistr. 52. 20246 Hamburg. Germany.

Michael Soyka. michael.soyka@pm-klinik.ch. Hospital Meiringen, PO Box 612, 3860 Meiringen, Switzerland.

Christoph Dilg. christoph.dilg@ukb.uni-bonn.de. Department of Psychiatry, University Hospital, Bonn. Germany.

Ingo Schäfer. i.schaefer@uke.uni-hamburg.de. Center for Interdisciplinary Addiction Research, University Medical Centre Eppendorf Hamburg, Martinistr. 52. 20246 Hamburg. Germany.

Jens Reimer. reimer@uke.uni-hamburg.de. Center for Interdisciplinary Addiction Research, University Medical Centre Eppendorf Hamburg, Martinistr. 52. 20246 Hamburg. Germany. 
Cite as: Haasen, C., Eiroa-Orosa, F. J., Verthein, U., Soyka, M., Dilg, C., Schäfer, I., \& Reimer, J. (2009).

Effects of heroin-assisted treatment on alcohol consumption: findings of the German randomized

controlled trial. Alcohol, 43(4), 259-264. https://doi.org/10.1016/j.alcohol.2009.02.007

\title{
Effects of heroin-assisted treatment on alcohol consumption: findings of the German \\ Randomized Controlled Trial
}

\begin{abstract}
Alcohol has been suggested to be a risk factor for opioid dependent patients in methadone maintenance treatment (MMT). Literature shows that MMT has limited effects on alcohol use. Nevertheless, a decrease in alcohol use was detected in the Swiss heroin-assisted treatment (HAT) study. In this paper we carry out an in-depth analysis of the German HAT trial with the aim of determining whether alcohol use was affected among patients undergoing heroin-assisted (HAT) and methadone maintenance treatment (MMT). Analysis was carried out using self reported data on consumption units of alcohol used (CU), Addiction Severity Index composite scores (ASI CS) and carbohydrate-deficient transferrin (CDT) measures. Results suggest significant reduction of CU and CDT in both groups, yet larger effects in the HAT group. ASI CS significantly decreased in the HAT but not in the MMT group. The greater benefit of HAT in reducing alcohol use may be due to the greater daily frequency of dispensing heroin coupled with a requirement of sobriety at each dosing occasion.
\end{abstract}

\section{Keywords}

Alcohol abuse, alcohol dependence, diamorphine, heroin-assisted treatment, methadone maintenance treatment. 
Cite as: Haasen, C., Eiroa-Orosa, F. J., Verthein, U., Soyka, M., Dilg, C., Schäfer, I., \& Reimer, J. (2009).

Effects of heroin-assisted treatment on alcohol consumption: findings of the German randomized

controlled trial. Alcohol, 43(4), 259-264. https://doi.org/10.1016/j.alcohol.2009.02.007

\section{Introduction}

Heroin-assisted treatment (HAT) has been implemented in clinical trials in Switzerland, the Netherlands, Spain, Germany, United Kingdom and Canada (Fischer et al., 2007).HAT has shown feasibility, effectiveness and safety in the Swiss, Dutch and Spanish trials (March et al., 2006; Rehm et al., 2001; van den Brink et al., 2003). In the German model project, HAT users showed better results than methadone maintenance treatment (MMT) in terms of health improvement and reduced illicit drug use (Haasen et al., 2007), and these results lasted over time (Verthein et al., 2008).

Concerning alcohol abuse and dependence in HAT patients, few results have been published. The Swiss study reported decreasing rates of occasional alcohol use whereas daily alcohol use remained approximately constant (Uchtenhagen et al., 1999). No reports of treatment effects on alcohol consumption have been published on the Dutch or Spanish HAT trials. The British and Canadian trials are currently in progress and no analyses have been published yet.

Effects of MMT on alcohol use have been analyzed in several studies. Srivastava et al. (2008) carried out a review of 14 longitudinally designed studies on the effects of MMT on alcohol use. Of the articles reviewed, nine found no change, three found an increase and another three articles a decrease in alcohol use. According to the authors, the studies that found no change or a decrease in alcohol use were stronger methodologically, as they were randomized controlled trials and prospective cohorts, whereas the studies that found an increase were all retrospective. Thus, although conclusions are complicated to make due to the heterogeneity of the reviewed studies, an increase of alcohol use was not considered to be probable. Using a two group design, Lollis et al. (2000) carried out a study where opioid 
Cite as: Haasen, C., Eiroa-Orosa, F. J., Verthein, U., Soyka, M., Dilg, C., Schäfer, I., \& Reimer, J. (2009).

Effects of heroin-assisted treatment on alcohol consumption: findings of the German randomized

controlled trial. Alcohol, 43(4), 259-264. https://doi.org/10.1016/j.alcohol.2009.02.007

dependent patients not in MMT reported significantly more alcohol intake than the group in MMT, confirming the hypothesis that patients in MMT are not likely to drink more.

The extent and reasons to which patients in MMT believed to change their drinking behavior during MMT were analyzed by Hillebrand et al. (2001). These authors found subjective norms (normative influence by "important others") and perceived functions of alcohol use (such as relaxing or empowering the effect of methadone) to be the strongest positive predictors. Bickel et al. (1987) reviewed treatments for alcoholic patients in MMT and found reduction both in alcohol and drug consumption in combined behaviouralpharmacological treatment but not in abstinence oriented, controlled drinking or voluntary disulfiram treatment.

Alcoholism has been suggested to be a relevant health risk factor for patients treated with methadone. Alcohol has been found to increase the risk of fatal opiate overdose (Hickman et al., 2008; Polettini et al., 1999; Ruttenber et al., 1990). A study carried out with 100 patients attending treatment showed that those who consumed alcohol had poorer diets and smoked more (Best et al., 1998). Another study (el-Bassel et al., 1993) pointed out the relationship between alcoholism and psychiatric symptomatology. The authors found higher rates of somatization, obsessive-compulsive behavior, depression, phobic anxiety, and psychosis in alcohol dependent than in non-dependent MMT patients. The higher prevalence of hepatitis C for MMT patients makes those who have an extensive history of alcohol use more vulnerable, leading to a poorer prognosis (Sylvestre, 2002) and even causing death (Zador and Sunjic, 2000). If treatment is intended, alcohol use can impair the efficacy of interferon-based treatments (Cooper and Mills, 2006). The absence of alcohol use has been also related to lower criminality in MMT clients (Patterson et al., 2000). 
Cite as: Haasen, C., Eiroa-Orosa, F. J., Verthein, U., Soyka, M., Dilg, C., Schäfer, I., \& Reimer, J. (2009).

Effects of heroin-assisted treatment on alcohol consumption: findings of the German randomized

controlled trial. Alcohol, 43(4), 259-264. https://doi.org/10.1016/j.alcohol.2009.02.007

Nevertheless, the literature suggests that there are no important interactions between alcoholism and MMT outcome. Rowan-Szal et al. (2000) reported no influence of alcohol use in an outpatient methadone treatment in terms of session attending and retention rate, even though they had lower levels of trust and respect for the counselors than other patients with no alcohol abuse. Chatham et al. Chatham (1995) found similar results and suggested that heavy drinking clients were significantly more likely to have prior experience with self-help groups and therefore, more capable to stay in treatment.

Considering the importance of addressing alcohol use in the treatment of opioid dependence, the effect of HAT compared to MMT on the possible reduction of alcohol use was analyzed as a secondary outcome measure in the German HAT trial.

\section{Materials and methods}

The original German trial sample was composed of 1015 heroin dependent patients, either not in treatment in the last 6 months or who were not responding to maintenance treatment. This sample was the result of an initial screening of 2083 heroin users, of which 1272 came to the initial baseline examination, 1032 fulfilled inclusion criteria and were randomized. 17 patients dropped out before treatment by withdrawing their consent. Finally 515 persons were randomized to the HAT group and 500 to the MMT group constituting the intention to treat sample (ITT). The treatment duration was 12 months, with $67.2 \%$ of HAT patients completing study treatment compared with $40.0 \%$ of MMT patients. The HAT patients received up to three times a day a maximum single intravenous dose of $400 \mathrm{mg}$ of diamorphine (=heroin) with a maximum daily dose of $1000 \mathrm{mg}$ (average dose: $442 \mathrm{mg} / \mathrm{d}$ ). A maximum of $60 \mathrm{mg}$ oral methadone was supplied if needed for take-home night use. MMT patients received one dose of oral methadone per day, which could be individually adjusted according to clinical judgement (average dose: $99 \mathrm{mg} / \mathrm{d}$ ). Methadone was dispensed upon 
Cite as: Haasen, C., Eiroa-Orosa, F. J., Verthein, U., Soyka, M., Dilg, C., Schäfer, I., \& Reimer, J. (2009).

Effects of heroin-assisted treatment on alcohol consumption: findings of the German randomized

controlled trial. Alcohol, 43(4), 259-264. https://doi.org/10.1016/j.alcohol.2009.02.007

daily attendance of a MMT clinic, take-home doses were only allowed in exceptional cases. A breath alcohol test of 0 was required before receiving methadone or diamorphine. Psychosocial treatment was also randomized within two groups. Patients received psychoeducation plus individual counseling or case management and motivational interviewing (for further details on the methodology of the trial see Haasen et al. (2007) and Degkwitz et al., (2007).

Data for the calculation of composite scores (ASI CS) according to the EuropASI (Kokkevi and Hartgers, 1995; based on the fifth edition of the Addiction Severity Index by McLellan et al., 1992; German version: Gsellhofer et al., 1999), was available for 965 patients at baseline (t-1) and 895 at the end of the 12 month period (t12), but only for 849 (ASI subsample) both at t-1 and t12. Self reported data on alcohol use in average units per day (CU, each unit=20g) was collected for 955 patients at $\mathrm{t}-1$ and 902 at $\mathrm{t} 12$, and only for 850 patients both at $\mathrm{t}-1$ and $\mathrm{t} 12$. Sample size differences are due to missing data.

As a biological marker of heavy alcohol use, carbohydrate-deficient transferrin (CDT) is widely used to monitor alcohol use in treatment (Anton, 2001). In this study it was used as an additional measure to assess changes in alcohol use. CDT blood measures were available only for part of the sample at $\mathrm{t}-1(\mathrm{n}=484)$ and $\mathrm{t} 12(\mathrm{n}=696)$ and only for 364 (CDT subsample) both at $\mathrm{t}-1$ and $\mathrm{t} 12$. CDT sample size was considerably smaller due to protocol violations (wrong laboratory units at baseline or not having completed CDT analyses in order to save costs). Furthermore, an ASI CS threshold of 0.17 for predicting alcohol dependence diagnosis has been recommended (Rikoon et al., 2006), while a cut-off of $3 \%$ is recommended for clinical relevance of CDT (Hock, 2005), both of which were used in this study.

Outcome was evaluated according to two primary outcome measures (see also Haasen et al. 2007): improvement of health and reduction of illicit drug use. Physical and mental 
Cite as: Haasen, C., Eiroa-Orosa, F. J., Verthein, U., Soyka, M., Dilg, C., Schäfer, I., \& Reimer, J. (2009).

Effects of heroin-assisted treatment on alcohol consumption: findings of the German randomized

controlled trial. Alcohol, 43(4), 259-264. https://doi.org/10.1016/j.alcohol.2009.02.007

health was based on the Opiate Treatment Index (OTI; Darke et al., 1992; 1991) health scale and Global Severity Index (GSI) of the Symptom Checklist-90-Revised (SCL-90-R; Derogatis, 1994).

\section{Results}

The main characteristics of the ITT sample and two subsamples can be seen in table 1 . Regarding sociodemographic characteristics and ASI CS at baseline, the two subsamples are fairly comparable to the ITT sample, with only one significant difference between treatment groups (HAT or MMT) in years of education in the CDT sample $(\mathrm{t}=2.33, \mathrm{df}=361, \mathrm{p}=0.02)$, where there is no difference in the ITT sample or ASI subsample. Main outcome information is also provided, with better outcome results for the HAT group in the ITT sample as well as in the two subsamples. CDT measures, ASI CS and CU showed significant correlations (Pearson, two tailed) both in $\mathrm{t}-1$ and $\mathrm{t} 12$ as shown in table 2. 
Cite as: Haasen, C., Eiroa-Orosa, F. J., Verthein, U., Soyka, M., Dilg, C., Schäfer, I., \& Reimer, J. (2009). Effects of heroin-assisted treatment on alcohol consumption: findings of the German randomized controlled trial. Alcohol, 43(4), 259-264. https://doi.org/10.1016/j.alcohol.2009.02.007

Table 1. Characteristics of the sample

\begin{tabular}{|c|c|c|c|c|c|c|}
\hline & \multicolumn{2}{|c|}{$\begin{array}{c}\text { Original ITT sample } \\
(n=1015)\end{array}$} & \multicolumn{2}{|c|}{ ASI subsample $(n=849)$} & \multicolumn{2}{|c|}{ CDT subsample $(n=364)$} \\
\hline & $\begin{array}{l}\text { Heroin } \\
\mathbf{n}=515\end{array}$ & $\begin{array}{c}\text { Methadone } \\
\mathbf{n}=\mathbf{5 0 0}\end{array}$ & $\begin{array}{c}\text { Heroin } \\
n=439\end{array}$ & $\begin{array}{l}\text { Methadone } \\
n=410\end{array}$ & $\begin{array}{l}\text { Heroin } \\
\mathrm{n}=\mathbf{1 8 2}\end{array}$ & $\begin{array}{c}\text { Methadone } \\
\mathbf{n}=\mathbf{1 8 2}\end{array}$ \\
\hline \multicolumn{7}{|c|}{ Sociodemographic characteristics } \\
\hline Male gender $(\%)$ & 80.0 & 79.8 & 81.3 & 78.3 & 80.2 & 81.3 \\
\hline Age $($ mean $\pm \mathrm{SD})$ & $36.2 \pm 6.7$ & $36.6 \pm 6.8$ & $36.4 \pm 6.7$ & $36.7 \pm 6.9$ & $36.5 \pm 6.3$ & $35.9 \pm 7.0$ \\
\hline $\begin{array}{l}\text { Education in years } \\
(\text { mean } \pm S D)\end{array}$ & $9.8 \pm 1.8$ & $9.7 \pm 1.9$ & $9.9 \pm 1.8$ & $9.7 \pm 1.9$ & $10.2 \pm 1.7$ & $9.7 \pm 2.0 *$ \\
\hline Employed (\%) & 13.6 & 12.3 & 13.7 & 13.2 & 17.0 & 15.5 \\
\hline Stable housing $(\%)$ & 69.0 & 69.7 & 69.9 & 71.4 & 72.5 & 67.4 \\
\hline $\begin{array}{l}\text { Duration of heroin } \\
\text { misuse (mean } \pm S D)\end{array}$ & $13.6 \pm 6.3$ & $13.6 \pm 6.3$ & $13.8 \pm 6.4$ & $13.6 \pm 6.3$ & $13.4 \pm 6.4$ & $13.1 \pm 6.4$ \\
\hline \multicolumn{7}{|c|}{ Selected Addiction Severity Index Composite Scores (ASI CS) at baseline, t-1 } \\
\hline $\begin{array}{l}\text { ASI CS for alcohol } \\
\text { misuse (mean } \pm \text { SD) }\end{array}$ & $.12 \pm .18$ & $.12 \pm .19$ & $.12 \pm .19$ & $.12 \pm .19$ & $.12 \pm .20$ & $.12 \pm .20$ \\
\hline $\begin{array}{l}\text { ASI CS for drug } \\
\text { misuse }(\text { mean } \pm S D)\end{array}$ & $.52 \pm .14$ & $.53 \pm .13$ & $.52 \pm .14$ & $.53 \pm .13$ & $.52 \pm .15$ & $.52 \pm .13$ \\
\hline $\begin{array}{l}\text { ASI CS for legal } \\
\text { problems (mean } \pm \\
\text { SD) }\end{array}$ & $.42 \pm .27$ & $.53 \pm .13$ & $.41 \pm .27$ & $.39 \pm .27$ & $.42 \pm .28$ & $.38 \pm .27$ \\
\hline \multicolumn{7}{|c|}{ Treatment outcome, t12 } \\
\hline Response in health & 80.0 & $74.0 *$ & 84.1 & $73.9 * * *$ & 84.1 & $74.2 *$ \\
\hline $\begin{array}{l}\text { Response in illicit } \\
\text { drug use }\end{array}$ & 85.2 & $65.8 * * *$ & 85.4 & $65.6 * * *$ & 85.2 & $69.8 * * *$ \\
\hline
\end{tabular}

\footnotetext{
$* \mathrm{p}<0.05$

$* * * \mathrm{p}<0.001$
}

Original ITT sample: Original Intention to Treat sample at t-1

ASI subsample: Patients whose Composite scores could be calculated both in $\mathrm{t}-1$ and $\mathrm{t} 12$

CDT subsample: Patients with available CDT data both at t-1 and t12 
Cite as: Haasen, C., Eiroa-Orosa, F. J., Verthein, U., Soyka, M., Dilg, C., Schäfer, I., \& Reimer, J. (2009). Effects of heroin-assisted treatment on alcohol consumption: findings of the German randomized controlled trial. Alcohol, 43(4), 259-264. https://doi.org/10.1016/j.alcohol.2009.02.007

Table 2. Correlation matrix (Pearson, two tailed) of alcohol measures at t-1 and t12

\section{CDT}

\section{ASI CS}

Baseline, $\mathrm{t}-1$

\begin{tabular}{|c|c|c|c|}
\hline CDT & 1 & & \\
\hline $\mathrm{CS}$ & $\mathrm{r}=0.400 * * *, \mathrm{n}=348$ & 1 & \\
\hline $\mathrm{CU}$ & $\mathrm{r}=0.248 * * *, \mathrm{n}=356$ & $\mathrm{r}=0.658 * * *, \mathrm{n}=961$ & 1 \\
\hline \multicolumn{4}{|c|}{12 Months, t12 } \\
\hline CDT & 1 & & \\
\hline CS 12 & $\mathrm{r}=0.479 * * *, \mathrm{n}=339$ & 1 & \\
\hline $\mathrm{CU}$ & $\mathrm{r}=0.403 * * *, \mathrm{n}=348$ & $\mathrm{r}=0.701 * * *, \mathrm{n}=895$ & 1 \\
\hline
\end{tabular}

CDT: Carbohydrate-Deficient Transferrin in \% of the total transferrin.

ASI CS: Addiction Severity Index (ASI) Composite Score.

CU: Consumption Units of alcohol.

$* * *$ Correlations significant $\mathrm{p}<0.001$, two tailed. 
Cite as: Haasen, C., Eiroa-Orosa, F. J., Verthein, U., Soyka, M., Dilg, C., Schäfer, I., \& Reimer, J. (2009).

Effects of heroin-assisted treatment on alcohol consumption: findings of the German randomized

controlled trial. Alcohol, 43(4), 259-264. https://doi.org/10.1016/j.alcohol.2009.02.007

Changes and differences in alcohol use

Table 3 shows the three measures for alcohol use and the results of independent t-tests at $\mathrm{t}-1$ and $\mathrm{t} 12$ and repeated measures ANOVAs carried out within treatment groups upon the three measures in order to explore time effects and between-group interactions. CDT measures showed both time and between-group significant interactions, with a stronger reduction in the HAT group. ASI CS had no overall time effect due to the missing reduction in the MMT group, but analysis was significant between groups CU reduction can be seen in both groups, represented by the overall time effect, but without between group interaction despite a greater reduction in the HAT group and significantly lower CU at $\mathrm{t} 12$. 
Cite as: Haasen, C., Eiroa-Orosa, F. J., Verthein, U., Soyka, M., Dilg, C., Schäfer, I., \& Reimer, J. (2009). Effects of heroin-assisted treatment on alcohol consumption: findings of the German randomized controlled trial. Alcohol, 43(4), 259-264. https://doi.org/10.1016/j.alcohol.2009.02.007

Table 3. Change in alcohol measures: means, standard deviations, t-tests and repeated measures analysis of variances

\begin{tabular}{|c|c|c|c|c|}
\hline & $\begin{array}{c}\text { HAT } \\
(\text { mean } \pm \text { SD })\end{array}$ & $\begin{array}{c}\text { MMT } \\
(\text { mean } \pm \text { SD })\end{array}$ & $\begin{array}{c}\text { Significance } \\
\text { T-test between } \\
\text { treatment groups }\end{array}$ & $\begin{array}{l}\text { Significance } \\
\text { RM ANOVA between } \\
\text { treatment groups }\end{array}$ \\
\hline CDT & $\mathrm{n}=182$ & $\mathrm{~N}=182$ & & \\
\hline$t-1$ & $3.06 \pm 2.19$ & $2.80 \pm 1.52$ & $\begin{array}{c}\mathrm{t}=1.379, \mathrm{df}=321.8 \\
\mathrm{p}=0.169\end{array}$ & $\begin{array}{l}\text { Time effect: } \\
\text { Pillai's Trace }=0.081, \mathrm{df}=1 \text {, } \\
\mathrm{p}=0.000\end{array}$ \\
\hline t12 & $2.24 \pm 1.2$ & $2.48 \pm 1.45$ & $\begin{array}{c}\mathrm{t}=-1.769, \mathrm{df}=350.5 \\
\mathrm{p}=0.078\end{array}$ & $\begin{array}{l}\text { Between-group interaction: } \\
\text { Pillai's Trace }=0.019, \mathrm{df}=1 \text {, } \\
\mathrm{p}=0.009\end{array}$ \\
\hline ASI CS & $\mathrm{n}=439$ & $\mathrm{~N}=410$ & & \\
\hline$t-1$ & $0.12 \pm 0.18$ & $0.12 \pm 0.19$ & $\begin{array}{c}\mathrm{t}=0.183, \mathrm{df}=963 \\
\mathrm{p}=0.855\end{array}$ & $\begin{array}{l}\text { Time effect: } \\
\text { Pillai's Trace }=0.001, \mathrm{df}=1, \\
\mathrm{p}=0.487\end{array}$ \\
\hline t12 & $0.09 \pm 0.18$ & $0.13 \pm 0.20$ & $\begin{array}{c}\mathrm{t}=-2.7, \mathrm{df}=852.3 \\
\mathrm{p}=0.007\end{array}$ & $\begin{array}{l}\text { Between-group interaction: } \\
\text { Pillai's Trace }=0.013, \mathrm{df}=1 \text {, } \\
\mathrm{p}=0.001\end{array}$ \\
\hline $\mathbf{C U}$ & $\mathrm{n}=468$ & $\mathrm{~N}=438$ & & \\
\hline$t-1$ & $6.67 \pm 12.11$ & $7.12 \pm 13.67$ & $\begin{array}{c}\mathrm{t}=-0.897, \mathrm{df}=994 \\
\mathrm{p}=0.370\end{array}$ & $\begin{array}{l}\text { Time effect: Pillai's } \\
\text { Trace }=0.026, \mathrm{df}=1, \mathrm{p}=0.000\end{array}$ \\
\hline t12 & $4.00 \pm 9.27$ & $5.69 \pm 11.51$ & $\begin{array}{c}\mathrm{t}=-2.182, \mathrm{df}=874.5 \\
\mathrm{p}=0.03\end{array}$ & $\begin{array}{l}\text { Between-group interaction: } \\
\text { Pillai's Trace }=0.002, \mathrm{df}=1 \text {, } \\
\mathrm{p}=0.136\end{array}$ \\
\hline
\end{tabular}

HAT: Heroin-Assisted Treatment group.

MMT: Methadone Maintenance Treatment group

t-1: Baseline

t12: Treatment after 12 months

RM ANOVA: Repeated measures analysis of variance 
Cite as: Haasen, C., Eiroa-Orosa, F. J., Verthein, U., Soyka, M., Dilg, C., Schäfer, I., \& Reimer, J. (2009).

Effects of heroin-assisted treatment on alcohol consumption: findings of the German randomized

controlled trial. Alcohol, 43(4), 259-264. https://doi.org/10.1016/j.alcohol.2009.02.007

\section{Interaction with treatment outcome}

The overall reduction in ASI CS for alcohol correlated slightly with reduction of ASI CS for drug use $(\mathrm{r}=.145, \mathrm{p}<0.001)$ and ASI CS for legal problems $(\mathrm{r}=0.152, \mathrm{p}<0.001) .17 .0 \%$ of the 696 patients with CDT measures at $\mathrm{t} 12$ and $26.1 \%$ of the 895 patients with ASI CS at t12 fulfilled criteria for alcohol dependence according to the recommended thresholds. Table 4 shows the different treatment outcomes after splitting the sample according to alcohol dependence using the two different thresholds. HAT patients had better outcomes in health improvement and in reduction of illicit drug use both for alcohol dependent and nondependent patients, with higher odds-ratios in the alcohol dependent sample when using the CDT threshold and higher odds-ratios for the non-dependent sample when using the ASI CS threshold. 
Table 4. Treatment outcome according to alcohol dependence (according to ASI CS and CDT thresholds) and treatment groups

\begin{tabular}{|c|c|c|c|c|c|c|c|c|c|c|c|}
\hline & & \multicolumn{2}{|c|}{ HAT } & \multicolumn{2}{|c|}{ MMT } & \multicolumn{2}{|c|}{ Total } & \multicolumn{2}{|c|}{$\begin{array}{l}\text { Significance between } \\
\text { treatment groups }\end{array}$} & \multicolumn{2}{|c|}{ Total significance (a) } \\
\hline & & $\mathrm{N}$ & $\%$ & $\mathrm{~N}$ & $\%$ & $\mathrm{~N}$ & $\%$ & OR & $95 \%$ CI & OR & $95 \% \mathrm{CI}$ \\
\hline \multirow[t]{4}{*}{$\begin{array}{l}\text { Response in health } \\
\text { improvement (n, } \\
\% \text { ) }\end{array}$} & $\begin{array}{l}\text { No alcohol } \\
\text { dependence } \\
\text { (ASI CS, } n=661 \text { ) }\end{array}$ & 307 & 85.8 & 233 & 76.9 & 540 & 81.7 & 1.808 & $1.213-2.695$ & \multirow[t]{2}{*}{1.794} & \multirow[t]{2}{*}{$1.291-2.493$} \\
\hline & $\begin{array}{l}\text { Alcohol } \\
\text { dependence } \\
\text { (ASI CS, } n=234)\end{array}$ & 80 & 76.9 & 85 & 65.4 & 165 & 70.5 & 1.765 & $0.986-3.158$ & & \\
\hline & $\begin{array}{l}\text { No alcohol } \\
\text { dependence } \\
\text { (CDT, } n=578)\end{array}$ & 266 & 85.3 & 197 & 74.1 & 463 & 80.1 & 2.025 & $1.336-3.070$ & \multirow[t]{2}{*}{2.110} & \multirow[t]{2}{*}{$1.442-3.086$} \\
\hline & $\begin{array}{l}\text { Alcohol } \\
\text { dependence } \\
\text { (CDT, n=118) } \\
\end{array}$ & 40 & 85.1 & 49 & 69.0 & 89 & 75.4 & 2.566 & $0.995-6.618$ & & \\
\hline \multirow[t]{4}{*}{$\begin{array}{l}\text { Response in } \\
\text { reduction of illicit } \\
\text { drug use (n, \%) }\end{array}$} & $\begin{array}{l}\text { No alcohol } \\
\text { dependence } \\
\text { (ASI CS, } n=661 \text { ) }\end{array}$ & 255 & 71.2 & 161. & 53.1 & 416. & 62.9 & 2.184 & $1.583-3.011$ & \multirow[t]{2}{*}{2.114} & \multirow[t]{2}{*}{$1.602-2.789$} \\
\hline & $\begin{array}{l}\text { Alcohol } \\
\text { dependence } \\
\text { (ASI CS, } n=234)\end{array}$ & 74 & 71.2 & 73 & 56.2 & 147 & 62.8 & 1.926 & $1.114-3.331$ & & \\
\hline & $\begin{array}{l}\text { No alcohol } \\
\text { dependence } \\
\text { (CDT, } n=578)\end{array}$ & 219 & 70.2 & 152 & 57.1 & 371 & 64.2 & 1.766 & $1.253-2.489$ & \multirow[t]{2}{*}{1.910} & \multirow[t]{2}{*}{$1.395-2.614$} \\
\hline & $\begin{array}{l}\text { Alcohol } \\
\text { dependence } \\
\text { (CDT, n=118) }\end{array}$ & 34 & 72.3 & 34 & 47.9 & 68 & 57.6 & 2.846 & $1.291-6.276$ & & \\
\hline
\end{tabular}

Alcohol dependence (ASI CS): ASI Composite score above 0.17 (26.1\% of $n=895)$.

Alcohol dependence (CDT): Carbohydrate-Deficient Transferrin \% value above 3 (17\% of $\mathrm{n}=696)$.

(a) Mantel-Haenszel Test between no alcohol dependence and alcohol dependence groups. 
Cite as: Haasen, C., Eiroa-Orosa, F. J., Verthein, U., Soyka, M., Dilg, C., Schäfer, I., \& Reimer, J. (2009).

Effects of heroin-assisted treatment on alcohol consumption: findings of the German randomized controlled trial. Alcohol, 43(4), 259-264. https://doi.org/10.1016/j.alcohol.2009.02.007

To assess the effects of alcohol dependence on health and illegal drug use outcomes at the end of treatment in both HAT and MMT groups, binary logistic regressions were carried out (results in table 5). Regarding health outcome, when a threshold of CDT over 3 was used, only treatment group $(\beta=.745, \mathrm{p}<.0001)$ was a reliable predictor of health outcome. When a threshold of ASI CS over 0.17 was used, improvement of health was predicted by both factors (alcohol dependence by ASI CS: $\beta=.576, p<.001$; treatment group: $\beta=.585, p<.0001$ ). No effect of alcohol dependence was detected in illegal drug use outcome both using CDT $(\beta=.190, \mathrm{p}=362)$ or ASI CS $(\beta=-.069, \mathrm{p}=.668)$ as predictors.

Table 5. Binary logistic regression models for health improvement and illegal drug use outcomes

\begin{tabular}{|c|c|c|c|c|c|c|c|}
\hline & Predictor & $\beta$ & Wald $\chi^{2}$ & df & OR & $95 \% \mathrm{CI}$ & $p$ \\
\hline \multirow{6}{*}{$\begin{array}{l}\text { Response in health } \\
\text { improvement }\end{array}$} & \multicolumn{7}{|c|}{ Model 1 (ASI CS over 0.17) } \\
\hline & \multirow{3}{*}{\multicolumn{2}{|c|}{$\begin{array}{lr}\text { Treatment group } & .585 \\
\text { Alcohol } & \\
\text { dependence } & .576 \\
\text { Model } 2 \text { (CDT over } 3)\end{array}$}} & 12.122 & 1 & 1.794 & \multirow{3}{*}{$\begin{array}{l}1.291-2.494 \\
1.258-2.517\end{array}$} & $<.0001$ \\
\hline & & & 10.627 & 1 & 1.780 & & .001 \\
\hline & & & & & & & \\
\hline & \multirow{2}{*}{$\begin{array}{l}\text { Treatment group } \\
\text { Alcohol } \\
\text { dependence }\end{array}$} & .745 & 14.774 & 1 & 2.107 & $1.441-3.080$ & $<.0001$ \\
\hline & & .173 & .515 & 1 & 1.189 & $0.741-1.910$ & .473 \\
\hline \multirow{6}{*}{$\begin{array}{l}\text { Response in } \\
\text { reduction of illicit } \\
\text { drug use }\end{array}$} & \multicolumn{7}{|c|}{ Model 1 (ASI CS over 0.17) } \\
\hline & \multirow{3}{*}{\multicolumn{2}{|c|}{$\begin{array}{lc}\text { Treatment group } & .749 \\
\text { Alcohol } & -.069 \\
\text { dependence } & \\
\text { Model 2 (CDT over 3) }\end{array}$}} & 28.020 & 1 & 2.115 & $1.603-2.791$ & $<.0001$ \\
\hline & & & .184 & 1 & .933 & $.681-1.279$ & .668 \\
\hline & & & & & & & \\
\hline & \multirow{2}{*}{$\begin{array}{l}\text { Treatment group } \\
\text { Alcohol } \\
\text { dependence }\end{array}$} & .647 & 16.311 & 1 & 1.910 & $1.395-2.614$ & $<.0001$ \\
\hline & & .190 & .829 & 1 & 1.210 & $.803-1.822$ & .362 \\
\hline
\end{tabular}

Alcohol dependence (ASI CS): ASI Composite score above 0.17 (26.1\% of $n=895)$.

Alcohol dependence (CDT): Carbohydrate-Deficient Transferrin \% value above 3. $(17.0 \%$ of $n=696)$.

\section{Discussion}

This is the first controlled study examining the effect of HAT on alcohol use among opioid dependent patients, as well as being a further study on the effect of MMT on alcohol use. Previous findings in methodologically stronger studies indicating a potentially positive 
Cite as: Haasen, C., Eiroa-Orosa, F. J., Verthein, U., Soyka, M., Dilg, C., Schäfer, I., \& Reimer, J. (2009).

Effects of heroin-assisted treatment on alcohol consumption: findings of the German randomized

controlled trial. Alcohol, 43(4), 259-264. https://doi.org/10.1016/j.alcohol.2009.02.007

effect of MMT on alcohol use was confirmed in part by our study, while HAT seems to have a significantly more positive effect of reducing alcohol use.

The reduction of alcohol use in the HAT group is confirmed by a reduction of CDT values, a reduction of ASI composite scores and also a reduction in number of alcohol units. In the MMT group there is a reduction of CDT values and number of alcohol units, but ASI composite scores were slightly higher at the end of the 12 month treatment period. Considering that ASI composite scores include other alcohol related problems, such as days intoxicated, the improvement with respect to the secondary measure alcohol use in the MMT group is not as clear as in the HAT group. This confirms the findings of the recent review on the effects of MMT on alcohol use (Srivastava et al., 2008), with an increase of alcohol use being improbable but also insufficient clear evidence of a reduction.

The stronger effect of HAT on a reduction of alcohol use could be explained on the one hand by a global positive effect on health status of the patients, as the primary outcome analysis of both mental and physical health showed significant improvement (Haasen et al., 2007), thereby decreasing the necessity of drinking if a perceived positive function of alcohol is expected to be a strong predictor (Hillebrand et al., 2001). When looking at the more severe cases of alcohol use, those considered to be alcohol dependent according to ASI composite scores and CDT thresholds, it becomes apparent that there is no interaction between alcoholism and treatment outcome regarding street heroin use, but there is an interaction with health outcomes. Whether it is the reduction of alcohol use that results in better overall health outcomes or it is the better health outcomes that lead to a reduction of alcohol use, needs to be analyzed in future studies. 
On the other hand, another main reason which could explain the reduction of alcohol use under HAT is the fact that diamorphine as well as methadone were only dispensed if patients were sober at that moment, forcing MMT patients to be sober in the mornings (once daily dispensing) and HAT patients to be sober up to three times a day. The fact that diamorphine needs to be dispensed three times a day (morning, midday and evening) due to the shorter half-life, increases the motivation to be sober not just in the morning. In general, HAT starts with three times daily dispensing, but most patients reduce their clinic visits to twice a day (morning and evening) for convenience reasons, nonetheless demanding soberness in the evening. The dispensing schedule therefore is a de facto behavioural contingency, and this structuring element seems to have a positive influence on treatment effects, similar to the effect in studies on contingency reinforcement in other substance use treatments (Rogers et al., 2008; Stitzer and Vandrey, 2008).

A limitation of the study is the lack of full data for all patients of the ITT sample, necessitating analyses of subsamples to determine the effects on alcohol use. However, data was missing to the same extent for both HAT and MMT groups. Furthemore, both the comparison of demographics of subsamples with ITT sample, showing no major differences, and the strong correlations shown between CDT values, ASI composite scores and number of drinking units, confirm the validity of the study measures.

Considering the multi-morbidity of severely opioid dependent patients, a stronger focus on secondary measures when evaluating maintenance treatment is of great importance. The negative health effect of alcohol use, especially the higher risk of fatal opiate overdose under the influence of alcohol (Hickman et al., 2008), therefore stands out as one of the most important factors to be addressed. The limited effect of MMT in this special group of patients 
Cite as: Haasen, C., Eiroa-Orosa, F. J., Verthein, U., Soyka, M., Dilg, C., Schäfer, I., \& Reimer, J. (2009).

Effects of heroin-assisted treatment on alcohol consumption: findings of the German randomized

controlled trial. Alcohol, 43(4), 259-264. https://doi.org/10.1016/j.alcohol.2009.02.007

warrants the introduction of alternatives, and HAT deserves to be considered as such an alternative due to the better results shown in this and previous studies.

\section{Acknowledgments}

We would like to thank patients and staff who participated in the study, as well as the Safety and Advisory Boards for their advice and support. The trial was commissioned and funded by a joint working group of the German Ministry of Health, the seven participating cities and the states of Hessen, Northrhine-Westphalia and Lower Saxony.

\section{References}

Anton, R.F. (2001). Carbohydrate-deficient transferrin for detection and monitoring of sustained heavy drinking: What have we learned? Where do we go from here? Alcohol $25,185-188$.

Best, D., Lehmann, P., Gossop, M., Harris, J., Noble, A., and Strang, J. (1998). Eating Too Little, Smoking and Drinking Too Much: Wider Lifestyle Problems Among Methadone Maintenance Patients. Addiction Res. Theor. 6, 489-498.

Bickel, W.K., Marion, I., and Lowinson, J.H. (1987). The treatment of alcoholic methadone patients: A review. J. Subst. Abuse Treat. 4, 15-19.

Chatham, L.R., Rowan Szal, G.A., G.W., J., Brown B.S., and D.D., S. (1995). Heavy drinking in a population of methadone-maintained clients. J. Stud. Alcohol 56, 417-422.

Cooper, C., and Mills, E. (2006). Therapeutic challenges in hepatitis C-infected injection drug using patients. Harm Red. 3, 31 .

Darke, S., Hall, W., Wodak, A., Heather, N., and Ward, J. (1992). Development and validation of a multi-dimensional instrument for assessing outcome of treatment among opiate users: the Opiate Treatment Index. Br. J. Addiction 87, 733-742. 
Cite as: Haasen, C., Eiroa-Orosa, F. J., Verthein, U., Soyka, M., Dilg, C., Schäfer, I., \& Reimer, J. (2009). Effects of heroin-assisted treatment on alcohol consumption: findings of the German randomized controlled trial. Alcohol, 43(4), 259-264. https://doi.org/10.1016/j.alcohol.2009.02.007

Darke, S., Ward, J., Zador, D., and Swift, G. (1991). A scale for estimating the health status of opioid users. Addiction 86, 1317-1322.

Degkwitz, P., Lichtermann, D., Deibler, P., Soyka, M., Schneider, U., Dieninghoff, D., Bonorden-Kleij, K., Köhler, W., Buhk, H., Verthein, U., et al. (2007). "Schwerstabhängige" - Die Teilnehmer des Modellprojekts zur heroingestützten Behandlung. Suchttherapie 8.

Derogatis, L.R. (1994). SCL-90-R: Administration, scoring and procedures manual. 3rd edition. Baltimore: Clinical Psychometric Research.

el-Bassel, N., Schilling, R., Turnbull, J., and Su, K. (1993). Correlates of Alcohol Use Among Methadone Patients. Alcohol. Clin. Exp. Res. 17, 681-686.

Fischer, B., Oviedo-Joekes, E., Blanken, P., Haasen, C., Rehm, J., Schechter, M., Strang, J., and van den Brink, W. (2007). Heroin-assisted Treatment (HAT) a Decade Later: A Brief Update on Science and Politics. J. Urban Health 84, 552-562.

Gsellhofer, B., Küfner, H., Vogt, M., and Weiler, D., eds. (1999). Nach der 5. Auflage der amerikanischen Version von McLellan und der Europäischen Version des ASI. Baltmannsweiler: Schneider Verlag Hohengehren.

Haasen, C., Verthein, U., Degkwitz, P., Berger, J., Krausz, M., and Naber, D. (2007). Heroinassisted treatment for opioid dependence: Randomised controlled trial. Br. J. Psychiatry 191, 55-62.

Hickman, M., Lingford-Hughes, A., Bailey, C., Macleod, J., Nutt, D., and Henderson, G. (2008). Does alcohol increase the risk of overdose death: the need for a translational approach. Addiction 103, 1060-1062.

Hillebrand, J., Marsden, J., Finch, E., and Strang, J. (2001). Excessive alcohol consumption 
Cite as: Haasen, C., Eiroa-Orosa, F. J., Verthein, U., Soyka, M., Dilg, C., Schäfer, I., \& Reimer, J. (2009). Effects of heroin-assisted treatment on alcohol consumption: findings of the German randomized controlled trial. Alcohol, 43(4), 259-264. https://doi.org/10.1016/j.alcohol.2009.02.007

and drinking expectations among clients in methadone maintenance. J. Subst. Abuse Treat. $21,155-160$.

Hock, B.S., M.; Domke, I.; Grunert, V. P.; Wuertemberger, M.; Schiemann, U.; Horster, S.; Limmer, C.; Stecker, G.; Soyka, M. (2005). Validity of carbohydrate-deficient transferrin (\%CDT), gamma-glutamyltransferase (gamma-GT) and mean corpuscular erythrocyte volume (MCV) as biomarkers for chronic alcohol abuse: a study in patients with alcohol dependence and liver disorders of non-alcoholic and alcoholic origin. Addiction 100, 1477-1486.

Kokkevi, A., and Hartgers, C. (1995). EuropASI: European adaptation of a multidimensional assessment instrument for drug and alcohol dependence. Eur. Addiction Res. 1, 208210.

Lollis, C.M., Strothers, H.S., Chitwood, D.D., and McGhee, M. (2000). Sex, Drugs, and HIV: Does Methadone Maintenance Reduce Drug Use and Risky Sexual Behavior? J. Behav. Med 23, 545-557.

March, J.C., Oviedo-Joekes, E., Perea-Milla, E., and Carrasco, F. (2006). Controlled trial of prescribed heroin in the treatment of opioid addiction. J. Subst. Abuse Treat.31, 203211.

McLellan, A.T., Kushner, H., Metzger, D., Peters, R., Smith, I., Grissom, G., Pettinati, H., and Argeriou, M. (1992). The fifth edition of the addiction severity index. J. Subst. Abuse Treat. 9, 199-213.

Patterson, S., Lennings, C.J., and Davey, J. (2000). Methadone Clients, Crime, and Substance Use. Int J Offender Ther. Comp. Criminol. 44, 667-680.

Polettini, A., Groppi, A., and Montagna, M. (1999). The Role of Alcohol Abuse in the 
Cite as: Haasen, C., Eiroa-Orosa, F. J., Verthein, U., Soyka, M., Dilg, C., Schäfer, I., \& Reimer, J. (2009). Effects of heroin-assisted treatment on alcohol consumption: findings of the German randomized controlled trial. Alcohol, 43(4), 259-264. https://doi.org/10.1016/j.alcohol.2009.02.007

Etiology of Heroin-Related Deaths. Evidence for Pharmacokinetic Interactions Between Heroin and Alcohol. J. Anal. Toxicol. 23, 570-576.

Rehm, J., Gschwend, P., Steffen, T., Gutzwiller, F., Dobler-Mikola, A., and Uchtenhagen, A. (2001). Feasibility, safety, and efficacy of injectable heroin prescription for refractory opioid addicts: a follow-up study. The Lancet 358, 1417-1420.

Rikoon, S.H., Cacciola, J.S., Carise, D., Alterman, A.I., and McLellan, A.T. (2006).

Predicting DSM-IV dependence diagnoses from Addiction Severity Index composite scores. J. Subst. Abuse Treat. 31, 17-24.

Rogers, R.E., Higgins, S.T., Silverman, K., Thomas, C.S., Badger, G.J., Bigelow, G., and Stitzer, M. (2008). Abstinence-contingent reinforcement and engagement in non-drugrelated activities among illicit drug abusers. Psychol Addict Behav 22, 544-550.

Rowan-Szal, G.A., Chatham, L.R., and Simpson, D.D. (2000). Importance of Identifying Cocaine and Alcohol Dependent Methadone Clients. American J. Addict. 9, 38 - 50. Ruttenber, J., Kalter, H.D., and Santinga, P. (1990). The role of ethanol abuse in the etiology of heroin related deaths. J. Forensic Sci. 35, 891-900.

Srivastava, A., Kahan, M., and Ross, S. (2008). The effect of methadone maintenance treatment on alcohol consumption: A systematic review. J. Subst. Abuse Treat. 34, 215-223.

Stitzer, M.L., and Vandrey, R. (2008). Contingency Management: Utility in the Treatment of Drug Abuse Disorders. Clin. Pharmacol. Ther. 83, 644-647.

Sylvestre, D.L. (2002). Treating hepatitis C in methadone maintenance patients: an interim analysis. Drug Alcohol Depend. 67, 117 - 123.

Uchtenhagen, A., Dobler-Mikola, A., Steffen, T., Gutzwiller, F., Blättler, R., and Pfeifer, S. 
Cite as: Haasen, C., Eiroa-Orosa, F. J., Verthein, U., Soyka, M., Dilg, C., Schäfer, I., \& Reimer, J. (2009). Effects of heroin-assisted treatment on alcohol consumption: findings of the German randomized controlled trial. Alcohol, 43(4), 259-264. https://doi.org/10.1016/j.alcohol.2009.02.007

(1999). Prescription of Narcotics for Heroin Addicts. Main Results of the Swiss National Cohort Study. Med. Prescr. of Narcotics, Vol 1. Zurich: Karger.

van den Brink, W., Hendriks, V.M., Blanken, P., Koeter, M.W.J., van Zwieten, B.J., and van Ree, J.M. (2003). Medical prescription of heroin to treatment resistant heroin addicts: two randomised controlled trials. BMJ 327, 310-312.

Verthein, U., Bonorden-Kleij, K., Degkwitz, P., Dilg, C., hler, W.K., Passie, T., Soyka, M., Tanger, S., Vogel, M., and Haasen, C. (2008). Long-term effects of heroin-assisted treatment in Germany. Addiction 103, 960-966.

Zador, D., and Sunjic, S. (2000). Deaths in methadone maintenance treatment in New South Wales, Australia 1990-1995. Addiction 95, 77-84. 